\title{
Multiple Skin Cancers Following Psoralen and Ultraviolet A Treatment of Psoriasis
}

\author{
Jin Seok Kang ${ }^{1}$, Sang Gue Kang ${ }^{1}$, Min Sung Tak ${ }^{1}$, Yoon Mi Jeen ${ }^{2}$ \\ Departments of ${ }^{1}$ Plastic and Reconstructive Surgery and ${ }^{2}$ Pathology, Soonchunhyang University Seoul Hospital, Soonchunhyang University College of Medicine, \\ Seoul, Korea
}

No potential conflict of interest relevant to this article was reported.

Psoriasis is a common inflammatory disease of the skin and joints. It usually occurs on the skin of the elbow and knee, but can involve any body surface area including scalp, hand, and foot. Psoriasis is a clinical diagnosis made from the presence of skin changes such as scaliness, redness, plaques, papules, or patches. This inflammatory condition has been associated with increased risks for cardiovascular disease, inflammatory bowel disease, and certain types of cancer. Currently, there is no consensus regarding the classification of its severity. However, percentage of body surface, psoriasis area severity index score, and dermatology life quality index score are widely used to classify its severity [1]. In moderate to severe psoriasis, there are multiple therapeutic options, including phototherapy, immunosuppressors, and biologic targeted therapy. Of these, the combination of psoralen and ultraviolet A (PUVA) has been used widely as an effective means to induce remission of psoriasis, but high-dose PUVA is reported to increase the risk of skin cancer [2]. In this report, we present a patient with psoriasis under long-term high-dose PUVA therapy who developed con-

\section{Correspondence: Sang Gue Kang}

Department of Plastic and Reconstructive Surgery, Soonchunhyang University Seoul Hospital, Soonchunhyang University College of Medicine, 53 Daesagwanro, Yongsan-gu, Seoul 140-743, Korea

E-mail: ksps1108@hanmail.net

*This work was supported by Soonchunhyang University Research Fund.

Received August 4, 2014 / Revised November 10, 2014

/ Accepted December 5, 2014 current squamous cell carcinoma (SCC) and basal cell carcinoma (BCC).

A 60-year-old woman presented to our hospital in September 2007 with a 3-month history of non-protruding hyperpigmented lesion on her left flank and right upper arm (Fig. 1). Her medical history was significant for psoriasis since childhood, for which she had received PUVA bath from 1984 to 1985 and 1989 to 1991. Punch biopsies revealed the right upper arm lesion as SCC (Fig. 2) and the flank lesion as BCC (Fig. 3). The patient underwent wide resections with free margins at two separate operations (September and October of 2007) (Fig. 4). Subsequent to this, the patient continued to present with worsening developing skin lesions for which she required 7 additional resections in various locations (breast, abdomen, and lower extremities). Histology of surgical specimens was consistent with BCC, SCC, Bowen's disease, and actinic keratosis (Table 1). The most recent operation was performed in August 2013 for three lesions in the right popliteal area (SCC). At the time of writing, the patient has skin lesions over the entire body and is being followed at the clinic on a regular basis.

Psoriasis can develop into a chronic inflammatory disease, which can markedly impact quality of life. Moderate to severe psoriasis often requires life-long systemic therapies to reduce symptoms. In the pathophysiology of psoriasis, abnormal over-activated T-cells will migrate into the skin and induce inflammatory and proliferative changes associated with the characteristic lesions. Cy- 

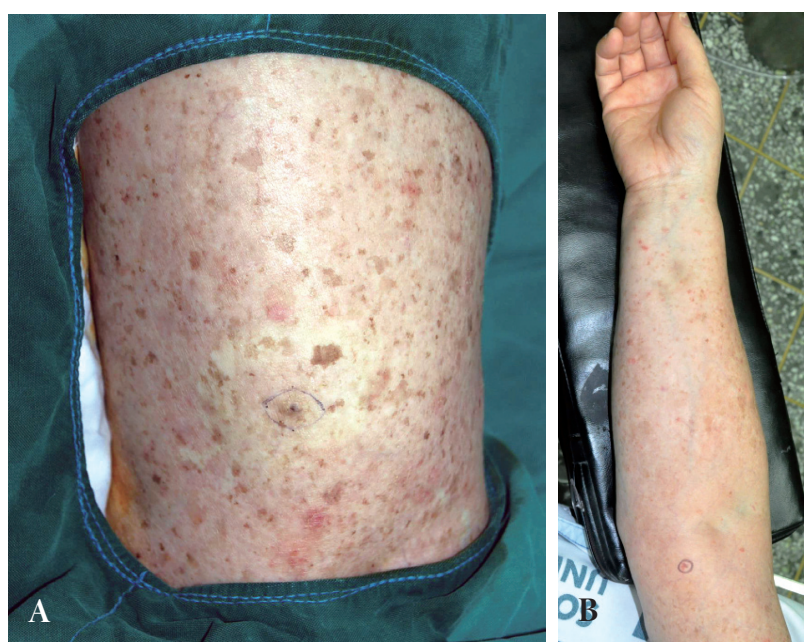

Fig. 1. Preoperative photographs. A $0.5 \times 0.5 \mathrm{~cm}$, non-protruding, fixed mass on (A) the left flank and (B) the right upper arm.

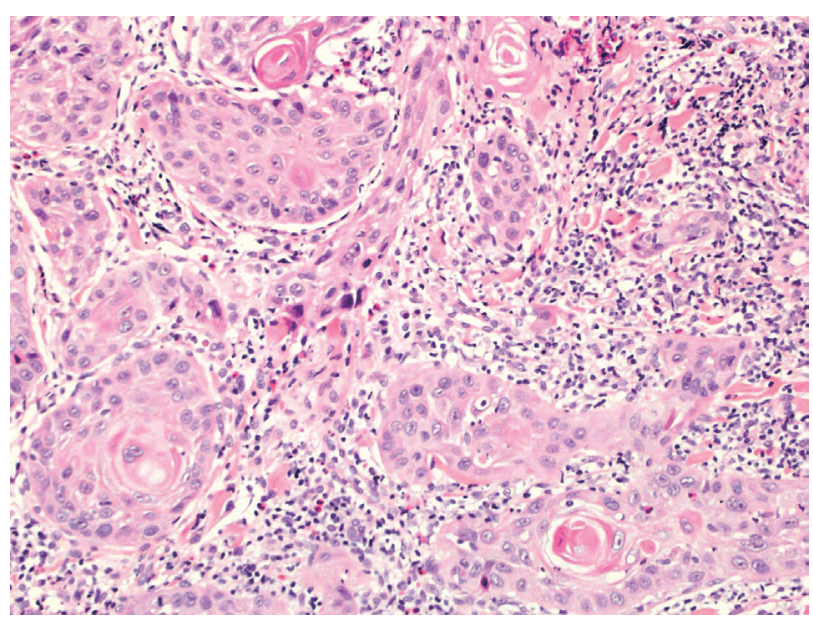

Fig. 2. Histopathologic image of the specimen from the right upper arm, showing moderately differentiated invasive squamous cell carcinoma with keratinization $(\mathrm{H} \& \mathrm{E}, \times 200)$.

tokines implicated in the pathogenesis of psoriasis include as interferon gamma (IFN- $\gamma)$, tumor necrosis factor alpha (TNF- $\alpha$ ), and interleukin 2(IL-2) [3].

Phototherapy is a widely used method with an unclear mechanism of action. In the past, PUVA therapy used to be the most common treatment of psoriasis. However, its application has been abandoned when it was found to increase the risk of SCC by more than a 100-fold [2]. The risk of secondary SCC and BCC after PUVA therapy was $75 \%$ and $61 \%$ at 10 years [4]. Subsequent to these findings, PUVA was replaced with ultraviolet B (UVB) therapy, which was not found to be associated with increased risk of SCC

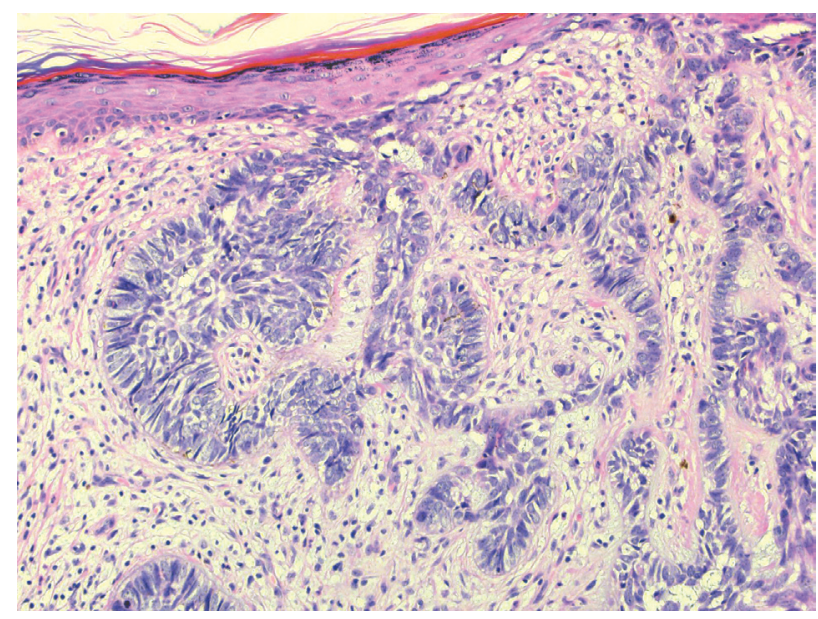

Fig. 3. Histopathologic image of the specimen from the left flank $(\mathrm{H} \& \mathrm{E}, \times 200)$. Basaloid tumor cells with peripheral palisading are arranged in a lace-like pattern.

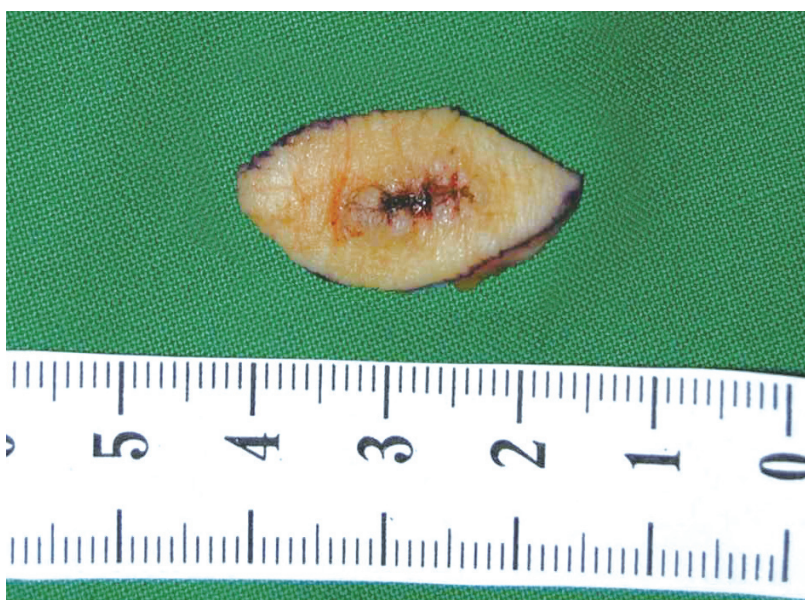

Fig. 4. Intraoperative specimen from the left flank. A $2.5 \times 1.5 \mathrm{~cm}$ mass.

[5]. Narrowband UVB has been known to be more effective than broadband UVB in terms of effectiveness and reducing complications such as erythema, hyperplasia, and edema [3].

Methotrexate, cyclosporine, and mycophenolatemofetil are immunosuppressors used in combination with PUVA and are associated with increased risk for lymphoproliferative disorders [5]. More recently, biologic target therapy including $\mathrm{T}$ cell modulators and TNF- $\alpha$ antagonists has been used for psoriasis therapy to inhibit T-cell activation and specific components of the inflammatory cascade. The risk of skin cancer with biologic therapy is unclear. However, TNF- $\alpha$ antagonists may cause a slightly increased risk of 
Table 1. Patient's operation history and pathologic finding

\begin{tabular}{|c|c|c|}
\hline Operation date & Location & Pathologic finding \\
\hline 2007.9 & Right upper arm & SCC \\
\hline 2007.10 & $\begin{array}{l}\text { Left flank } \\
\text { Right lower leg } \\
\text { Right thigh }\end{array}$ & $\begin{array}{l}\text { BCC } \\
\text { Epitehlial dysplasia } \\
\text { Acanthosis }\end{array}$ \\
\hline 2008.1 & $\begin{array}{l}\text { Abdomen } \\
\text { Right thigh }\end{array}$ & $\begin{array}{l}\text { BCC, Lentiginous melanocytic } \\
\text { proliferation } \\
\text { Bowen's disease }\end{array}$ \\
\hline 2009.5 & Right breast & $\mathrm{BCC}$ \\
\hline 2009.12 & $\begin{array}{l}\text { Left thigh } \\
\text { Left breast }\end{array}$ & $\begin{array}{l}\text { Bowen's disease } \\
\text { BCC }\end{array}$ \\
\hline 2010.7 & $\begin{array}{l}\text { Abdomen } \\
\text { Left thigh }\end{array}$ & $\begin{array}{l}\text { BCC } \\
\text { Actinic keratosis }\end{array}$ \\
\hline 2012.5 & $\begin{array}{l}\text { Ritht thigh } \\
\text { Abdomen }\end{array}$ & $\begin{array}{l}\text { SCC } \\
\text { Bowen's disease }\end{array}$ \\
\hline 2013.8 & Right lower leg & SCC, Bowen's disease \\
\hline
\end{tabular}

SCC, squamous cell carcinoma; BCC, basal cell carcinoma.

non-melanocytic skin cancer [5].

In our case, the patient was treated with high-dose PUVA therapy for severe psoriasis on two separate occasions more than two decades ago. In that era, the risk of malignancy with PUVA therapy was not widely known. Unfortunately, the patient suffers from unremitting number of non-melanocytic skin cancers. Because the risk for BCC following high-dose PUVA therapy was much less dramatic than the risk of SCC [2], the occurrence of concurrent skin cancer lesion is very rare and significant. In the case presented here, we recognized that close inspection of various skin lesions is very important. Patients with history of high-dose PUVA treatment should be monitored closely for occurrence of skin cancers even if the treatment had been decades ago.

\section{REFERENCES}

1. Menter A, Gottlieb A, Feldman SR, Van Voorhees AS, Leonardi CL, Gordon KB, Lebwohl M, Koo JY, Elmets CA, Korman NJ, Beutner KR, Bhushan R. Guidelines of care for the management of psoriasis and psoriatic arthritis: Section 1. Overview of psoriasis and guidelines of care for the treatment of psoriasis with biologics. J Am Acad Dermatol 2008;58:826-50.

2. Stern RS, Liebman EJ, Vakeva L. Oral psoralen and ultraviolet-A light (PUVA) treatment of psoriasis and persistent risk of nonmelanoma skin cancer. PUVA Follow-up Study. J Natl Cancer Inst 1998;90:127884 .

3. Jiaravuthisan MM, Sasseville D, Vender RB, Murphy F, Muhn CY. Psoriasis of the nail: anatomy, pathology, clinical presentation, and a review of the literature on therapy. J Am Acad Dermatol 2007;57:1-27.

4. Katz KA, Marcil I, Stern RS. Incidence and risk factors associated with a second squamous cell carcinoma or basal cell carcinoma in psoralen + ultraviolet a light-treated psoriasis patients. J Invest Dermatol 2002;118:1038-43.

5. Patel RV, Clark LN, Lebwohl M, Weinberg JM. Treatments for psoriasis and the risk of malignancy. J Am Acad Dermatol 2009;60:1001-17. 